Protestantismo em Revista é licenciada sob uma Licença Creative Commons.

http://dx.doi.org/10.22351/nepp.v43i01.2937

\title{
Pluralidade religiosa brasileira: a importância do diálogo inter-religioso
}

\author{
Brazilian religious plurality: \\ the importance of inter-religious dialog
}

Airton Vitorino da Silva*

Claudete Beise Ulrich**

\begin{abstract}
Resumo
É fundamental para uma convivência humana fraterna o reconhecimento da pluralidade. O Brasil possui uma rica diversidade cultural e religiosa. No entanto, percebe-se, por parte de alguns grupos, a intolerância religiosa, a falta de respeito à alteridade. Isto se manifesta, especialmente, em relação às religiões de matriz africana. $\mathrm{O}$ diálogo inter-religioso se apresenta como um elemento fundamental para a superação da intolerância religiosa. Conhecer o outro, numa relação de alteridade respeitosa, conduz para uma convivência de compromisso e cuidado com as pessoas e com toda a criação.
\end{abstract}

Palavras-chave

Pluralidade Religiosa Brasileira. Intolerância Religiosa. Diálogo InterReligioso.

\begin{abstract}
It is essential for a fraternal human society to recognize the plurality. Brazil has a rich cultural and religious diversity. However, it is perceived, by some religious groups, religious intolerance, and lack of respect for otherness. This is especially true for religions of African origin. Interreligious dialogue is a fundamental element in overcoming religious intolerance. Knowing the other, in a relation of respectful alterity, leads to a coexistence of commitment and care with people and with all creation.
\end{abstract}

Keywords

Brazilian religious plurality. Religious intolerance. Inter-Religious dialogue.

[Texto recebido em janeiro de 2017 e aceito em junho de 2017, com base na avaliação cega por pares realizada por pareceristas ad hoc]

* Bacharel em Teologia (Faculdade Evangélica de Belo Horizonte). Pós-Graduado em Educação Religiosa Escolar e Teologia Comparada (Escola Superior Aberta do Brasil). Mestrado em Ciências das Religiões (Faculdade Unida de Vitória). E-mail: pr.airtonvitorino@yahoo.com.br

** Doutora em Teologia. Docente do Programa de Pós-Graduação em Ciências das Religiões (Faculdade Unida de Vitória). E-mail: claudetebeiseulrich@hotmail.com 


\section{Introdução}

Busca-se neste artigo refletir sobre a importância do Diálogo Inter-Religioso, considerando a pluralidade religiosa brasileira. $\mathrm{O}$ reconhecimento da diversidade religiosa intensifica mais do que nunca; marca e desafia a necessidade do diálogo e do respeito mútuo entre as diferentes tradições religiosas. Na realidade brasileira, no entanto, há por parte de alguns grupos cristãos uma grande intolerância religiosa, que se mostra, especialmente, em relação às religiões de matriz africana.

Como não impor a outra pessoa a sua tradição religiosa cristã? Como construir um diálogo respeitoso entre pessoas que participam de comunidades de tradições de fé diferentes? Como superar a violência, fruto da intolerância religiosa tão presente na realidade brasileira? Estas perguntas motivaram o presente artigo, fundamentado em referências bibliográficas, especialmente, análise do Censo do IBGE 2010, Ricardo Mariano, Faustino Teixeira, Cláudio de Oliveira Ribeiro, entre outros.

O respeito às diferenças é fundamental para a vivência cidadã e democrática. Dialogar é aproximar-se, conhecer, ouvir com atenção, valorizar, admirar-se com as experiências das outras pessoas, caminhar junto. Apresenta-se, primeiramente, uma reflexão sobre a pluralidade religiosa brasileira, procura-se, então, entender o diálogo inter-religioso. Por fim, aponta-se para a importância da ação dialogal, isto é, para a vivência respeitosa entre as diferentes tradições religiosas, como uma das formas de superar a intolerância religiosa.

\section{Pluralidade religiosa brasileira}

O Brasil contemporâneo é marcado pela pluralidade religiosa. Percebem-se mudanças na mobilidade religiosa, especialmente, a partir dos últimos censos realizados no Brasil. O Censo de 2000 apresentou uma acentuada redução das pessoas ligadas à religião católica. Segundo análise dos dados do próprio IBGE:

O Censo Demográfico 2000 mostrou acentuada redução do percentual de pessoas da religião católica romana, o qual passou a ser de 73,6\%, o aumento do total de pessoas que se declararam evangélicas, $15,4 \%$ da população, e sem religião, $7,4 \%$ dos residentes. Observou-se, ainda, o ligeiro crescimento dos que se declararam espíritas (de 1,1\%, em 1991,para $1,3 \%$ em 2000) e do conjunto de outras religiosidades que se elevou de $1,4 \%$, em 1991, para $1,8 \%$ em 2000.1

O número de pessoas católicas passou a ser de 73,6\%, já em relação aos evangélicos aconteceu um aumento, passando para 15,4\% e aumentando os sem religião

1 INSTITUTO BRASILEIRO DE GEOGRAFIA E ESTATÍSTICA - IBGE. Censo Demográfico 2010: características gerais da população, religião e pessoas com deficiência. Rio de Janeiro: IBGE: Censo demográfico, 2010. p. 90. 
para 7,4\%. É interessante também observar um aumento das pessoas que se declararam espíritas, passando de 1,1\% para 1,3\%. Também pessoas ligadas a outras religiosidades aumentaram, de 1,4\% indo para 1,8\%. É interessante observar que o censo de 2000 pela primeira vez registra esta queda do catolicismo e um aumento dos evangélicos e dos sem religião. Em relação ao Censo de 2010, o pesquisador Ricardo Mariano afirma:

Os dados do Censo 2010 sobre religião confirmam as tendências de transformação do campo religioso brasileiro, mutação que se acelerou a partir da década de 1980, caracterizando-se, principalmente, pelo recrudescimento da queda numérica do catolicismo e pela vertiginosa expansão dos pentecostais e dos sem religião. [...] De 1980 para cá, portanto, prosperou a diversificação da pertença religiosa e da religiosidade no Brasil, mas se manteve praticamente intocado seu caráter esmagadoramente cristão. ${ }^{2}$

A partir da década 1980 percebe-se uma mudança no cenário religioso brasileiro. Brasil torna-se mais diversificado, mas continua sendo em sua maioria cristão. A diversificação acontece, especialmente, em relação ao crescimento dos evangélicos e dos sem religião. De acordo com Mariano:

A rápida redução do peso da hegemonia católica no país decorreu diretamente, mas não exclusivamente, do crescimento acelerado de seus concorrentes religiosos, sobretudo das igrejas pentecostais, e do avanço dos sem religião, grupo heterogêneo composto por agnósticos, ateus e, sobretudo, por indivíduos que passaram a declarar não dispor de filiação religiosa, autoidentificação que, em sua maioria, não significa necessariamente descrença ou indiferentismo religioso. A expansão dos demais grupos religiosos minoritários pesou muito pouco para o declínio do catolicismo. ${ }^{3}$

Cresceu no país pessoas que se assumiram participantes das igrejas pentecostais e as pessoas que se afirmaram sem religião. O grupo dos sem religião, segundo o pesquisador, é um grupo heterogêneo composto por agnósticos, ateus e por pessoas que afirmaram não ter nenhuma afiliação religiosa. No entanto, isto não significa que este grupo seja descrente ou que tenha um indiferentismo religioso. Estes dois grupos, pentecostais e sem religião, são os que marcaram o declínio do catolicismo no Brasil. Sobre o Censo 2010, segundo a análise do IBGE:

[...] o crescimento da diversidade dos grupos religiosos no Brasil, revelando uma maior pluralidade nas áreas mais urbanizadas e populosas do País. A proporção de católicos seguiu a tendência de redução observada

2 MARIANO, Ricardo. Mudanças no campo religioso brasileiro no Censo 2010. Debates do NER, Porto Alegre, ano 14, n. 24, p. 119, jul./dez. 2013. Disponível em: <http://www.seer.ufrgs.br/debatesdoner/article/download/43696/27488>. Acesso em: 20 dez. 2016.

3 MARIANO, 2013, p. 120. 
nas duas décadas anteriores, embora tenha permanecido majoritária. Em paralelo, consolidou-se o crescimento da parcela da população que se declarou evangélica. Os dados censitários indicam também o aumento do total de pessoas que professam a religião espírita, dos que se declararam sem religião, ainda que em ritmo inferior ao da década anterior e do conjunto pertencente a outras religiosidades. ${ }^{4}$

Importante destacar que o crescimento da diversidade dos grupos religiosos no Brasil apresenta uma maior pluralidade nas áreas mais urbanizadas e populosas do país. Isto, no entanto, não significa que a presença de grupos pentecostais e de pessoas sem religião não são encontradas na área rural ou em pequenas cidades. ${ }^{5}$ Mariano entende que:

A desmonopolização e a destradicionalização religiosas estão associadas à pluralização religiosa e à intensificação da concorrência no e por mercado religioso, mas também à crescente opção individual de não filiar-se ou de se afastar de instituições religiosas. ${ }^{6}$

Segundo o autor, a pluralidade religiosa e as disputas no e por mercado religioso, o crescimento da autonomia do sujeito em optar individualmente em pertencer ou não pertencer a uma instituição religiosa tem gerado a desmonopolização e destradicionalização. Mesmo que ainda haja o monopólio do cristianismo no Brasil, mas a forma como ele se apresenta é muito diversificada, passando um processo de destradicionalização. O monopólio do sagrado também está em processo de migração, percebe-se isto no aumento daquelas pessoas que se declararam sem religião. Ainda de acordo com Mariano:

Fenômenos que vêm sendo reforçados pelo avanço da afirmação da liberdade individual como valor e como prática legítima, e pelo fato de que a liberdade e o pluralismo religiosos - conforme sustenta a tese principal de Peter Berger (1985) em O dossel sagrado - tendem a fazer com que a religião seja encarada mais e mais como uma questão de livre escolha ou preferência pessoal, algo que, na prática, tem sido evidenciado sobejamente pelo intenso e crescente trânsito religioso no país. ${ }^{7}$

Portanto, segundo Mariano, o trânsito religioso no Brasil, a partir de Berger, pode ser visto como uma questão da livre escolha ou preferência pessoal do sujeito. João Batista Libâneo reforça esta tese afirmando que:

O pluralismo, no campo religioso brasileiro, seria um reflexo de, pelo menos, dois fatores: a existência da diversidade e a reivindicação da liberdade religiosa. O pluralismo é uma condição social própria de

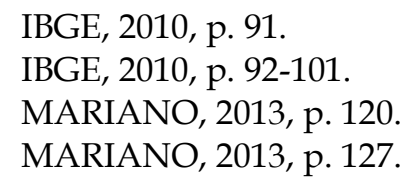


sociedades onde não há hegemonia religiosa ou onde a hegemonia religiosa tende a desaparecer. ${ }^{8}$

O pluralismo religioso é fruto da diversidade e liberdade religiosas que se vive no Brasil. A hegemonia religiosa, que uma vez era do catolicismo, está diminuindo. Celso Gabatz afirma que o "reconhecimento do pluralismo representa a democratização do campo religioso, em que todos os sujeitos são reconhecidos como legítimos em suas reivindicações, desde que respeitados os seus princípios éticos" ${ }^{9}$ Portanto, o pluralismo religioso aponta para uma sociedade democrática e plural. Ao apontar para uma sociedade plural, cidadã, democrática, o pluralismo religioso aposta em processos de autonomia e de emancipação do sujeito.

A autonomia do sujeito em suas decisões pessoais é um dos elementos que fortalecem a pluralidade religiosa. Diante desta realidade, percebe-se, especialmente, disputas entre grupos religiosos que pretendem moralizar a conduta individual, controlar a sexualidade, sendo contra o aborto, rechaçando a diversidade sexual, modelos diferentes de família. Buscam determinar padrões de convivência de acordo com princípios bíblicos fundamentados numa leitura descontextualizada. Portanto, por um lado, há a emancipação do sujeito em suas próprias escolhas não mais ditadas por comunidades religiosas e, por outro lado, há grupos religiosos que se colocam como os defensores da moral. Conforme Teixeira, "o fato é que o pluralismo religioso impõe-se hoje como um componente 'intransponível', que desafia todas as religiões ao exercício fundamental do diálogo".10 As barreiras culturais e a imposição pela força são ações antagônicas, que podem ser transpostas pelo viés do entendimento. Render-se ao dialogo é o maior sucesso de compreensão do seu diferente. O que é intransponível somente prevalece até que o diálogo entre em ação.

Desse modo, o pluralismo religioso brasileiro, que se apresentou de forma mais consistente nas últimas décadas, é também um campo ${ }^{11}$ em disputa, onde a intolerância religiosa se apresenta de forma violenta especialmente contra religiões de matriz africana que já não aceitam mais se esconder, pois a liberdade religiosa é um direito constitucional. No entanto, grupos não cristãos, dentro de uma hegemonia cristã, ainda são vistos como suspeitos ou como possíveis pessoas a serem convertidas, especialmente por grupos pentecostais em ascensão no cenário religioso brasileiro. Claudio de Oliveira Ribeiro aponta para o fato de que:

8 LIBÂNEO apud GABATZ, Celso. Religiosidade Brasileira Contemporânea: Pluralismo, secularização e múltiplas pertenças. Anais do Congresso Internacional da Faculdades EST. v. 2. São Leopoldo: EST, 2014. p. 513. Disponível em: <http://anais.est.edu.br/index.php/congresso/article/viewFile/256/218>.

9 GABATZ, 2014, p. 513.

10 TEIXEIRA, Faustino. O diálogo inter-religioso. In: TEIXEIRA, Faustino; DIAS, Zwinglio Mota. Ecumenismo e diálogo inter-religioso: a arte do possível. Aparecida: Santuário, 2008. p. 119.

11 BOURDIEU, Pierre. A economia das trocas simbólicas. São Paulo: Perspectivas, 2007. p. 57-69. No campo religioso, vários agentes especializados disputam o privilégio exclusivo dos bens de salvação. 
A dinâmica da globalização e de pluralismo por que passa a sociedade contemporânea afetou vários segmentos da sociedade, e de forma especial a religião. Os fundamentalismos, por exemplo, encontram-se diante de um desafio: dialogar com outros grupos e rever conceitos que já não fazem mais sentido no contexto atual. Para as práticas religiosas, assim como para as análises científicas sobre a religião, a comunicação dialógica se faz necessária e o alargamento das fronteiras é imprescindível. Dificilmente haverá espaço na sociedade para interpretações singulares e herméticas, que privilegiam determinadas tradições..$^{12}$

O pluralismo religioso apresenta como exigência o diálogo entre as diferentes tradições e culturas religiosas e o alargamento das fronteiras. $O$ diálogo necessita acontecer não somente entre as diferentes tradições religiosas, mas também com toda a sociedade que nem sempre está aberta à alteridade e ao diálogo respeitoso com aqueles e aquelas que expressam a sua fé de forma diferente do que a maioria, no caso do Brasil, a religião de matriz cristã. Na mesma direção de Ribeiro, Teixeira afirma que a

[...] alteridade que nem sempre vem acolhida em sua positividade. Deve-se sublinhar a presença tensa de valores e crenças em viva competividade, em que são usados vários estratagemas para garantir a plausibilidade e expansão de uma internalização religiosa sempre ameaçada. Se de um lado o pluralismo pode significar a abertura a uma nova conversação dialogal e certo grau de tolerância, ele tende também a acentuar as heranças confessionais e as dissonâncias cognitivas. ${ }^{13}$

Neste sentido, o diálogo inter-religioso apresenta-se como uma ferramenta importante para o encontro respeitoso entre as diferentes tradições religiosas que compõem a rica pluralidade religiosa brasileira.

\section{Diálogo inter-religioso: sua importância}

O que vem a ser concretamente o diálogo inter-religioso? De acordo com Faustino Teixeira:

Dentre a extensa variedade de formas de diálogo, situa-se o diálogo interreligioso com sua peculiaridade própria. Trata-se de um relacionamento entre fiéis que estão domiciliados em sua própria fé, mas também abertos aos amigos de outras tradições religiosas. Envolve sempre compreensão mútua e recíproco enriquecimento. Quando se fala em mútuo conhecimento defronta-se com um desafio extremamente delicado: "a arte de compreender". ${ }^{14}$

12 RIBEIRO, Claudio de Oliveira. Pluralismo e libertação. São Paulo: Paulinas, 2014. p. 38.

13 TEIXEIRA, 2008, p. 119.

14 TEIXEIRA, Faustino. Teologia e diálogo inter-religioso. ALMEIDA, Edson Fernando de; LONGUINI NETO, Luiz (Orgs.), Teologia para quê? Rio de Janeiro: Mauad, 2007. p. 74. 
O diálogo inter-religioso direciona para o encontro de pessoas que a partir da sua fé se encontram e dialogam com pessoas de outras tradições religiosas. $\mathrm{O}$ diálogo interreligioso se caracteriza pela abertura ao outro, tendo como característica a compreensão mútua e o recíproco enriquecimento. Um aprende do outro. No diálogo inter-religioso, nenhuma pessoa tenta impor a sua fé, mas ele está baseado, como afirma Teixeira, na arte de compreender o outro. Um dos fundamentos do diálogo inter-religioso é a alteridade. Ainda de acordo com Teixeira:

O diálogo inter-religioso traduz a riqueza de um novo aprendizado: a relação com a diferença e a alteridade significa a "apropriação de outras possibilidades" e a "abertura à mútua transformação". Este desafio dialogal, complexo e laborioso, é imprescindível para as religiões. $\mathrm{Na}$ ausência deste intercâmbio criativo as religiões fragilizam-se, carecendo da atmosfera essencial para a sua afirmação e crescimento. ${ }^{15}$

É na relação respeitosa com o outro que o autoconhecimento também se realiza. Quando se negligencia o intercâmbio criativo entre as religiões, elas se tornam guetos, considerando-se portadoras de verdades únicas, fortalecendo a intolerância religiosa, gerando violências, como a que temos assistido no Brasil, especialmente, contra as religiões de matriz africana. ${ }^{16}$ De acordo com Teixeira:

O teólogo indiano, Raimundo Panikkar, vem sinalizando em sua reflexão a importância essencial deste intercâmbio vital entre as religiões: um intercâmbio que possibilita o encontro da religião consigo mesma. Não há para ele como entender a fundo uma determinada tradição senão mediante a abertura, conhecimento, e diálogo com outros universos religiosos. ${ }^{17}$

Importante destacar que somente conhece-se a fundo a sua própria religião quando esta entra em diálogo com uma outra tradição religiosa. Todas as tradições religiosas são construções humanas. Nenhuma tradição religiosa é perfeita. Com o diálogo inter-religioso uma pode aprender da outra, para que isto ocorra, é necessário sensibilidade, ouvido atento, vontade de aprender da outra pessoa e respeito. Nessa direção, Teixeira afirma que:

O diálogo requer "cortesia espiritual" e abertura do coração. Requer igualmente uma espécie de conversão ao universo do outro. Isto não é uma

15 TEIXEIRA, 2007, p. 74.

16 Veja o texto, por exemplo, de MACHADO, Gerson. Violência contra os Axés. Reflexus - Revista Semestral de Teologia e Ciências das Religiões, v. 9, n. 14, p. 257-273, 2015. Disponível em: <http://revista.faculdadeunida.com.br/index.php/reflexus/article/view/296/295>. Acesso em: 20 jan. 2016.

17 TEIXEIRA, 2007, p. 75. 
tarefa fácil, mas um processo que pressupõe um indispensável estado espiritual de desapego e hospitalidade. ${ }^{18}$

O diálogo inter-religioso aponta para o pluralismo religioso. Abrir-se para a pluralidade requer uma mudança em direção ao universo do outro. Como afirma Claude Geffré: "a pluralidade dos caminhos que levam a Deus continua sendo um mistério que nos escapa". ${ }^{19}$ Este processo de abertura ao outro não é fácil, pois o "pluralismo provoca em indivíduos ou grupos um sentimento de insegurança significativamente ameaçador para a plausibilidade de sua inserção no mundo" ${ }^{20}$

O diálogo inter-religioso é uma dinâmica nova que está ganhando força diante da diversidade cultural religiosa, do radicalismo tradicional, do ceticismo moderno; demonstrando interesse em busca de compreensão, paz, harmonia para a convivência sem conflito. Roberlei Panasiewicz define da seguinte forma o encontro com o outro: "o homem constrói a si mesmo na relação com o outro, e ambos descobrem outro si deles mesmo, a partir desse encontro". ${ }^{21}$ Para Panasiewicz: "o pluralismo religioso não descaracteriza Deus; pelo contrário, expressa o mistério de sua transcendência, que religião nenhuma, mesmo com o seu sistema de doutrinas, ritos e normas, consegue capturar. $^{22} \mathrm{O}$ mistério do sagrado encontra-se em todas as religiões. Portanto, urge colocar em pauta o diálogo inter-religioso para ancorar a concretização da justiça, da paz, da defesa do meio ambiente e da construção da consciência cidadã no exercício do respeito e da alteridade.

\section{Eixos centrais do diálogo inter-religioso}

Os eixos centrais do diálogo inter-religioso implicam a consciência da humildade. É necessário desenvolver "uma disponibilidade interior de abertura e acolhimento" ${ }^{23}$ Isto significa acolher o outro que pensa e confessa a fé diferente com respeito, com ouvido atento, com interesse, com atenção, com vontade de aprender. Teixeira diz que "o sentimento de superioridade constitui um real obstáculo ao diálogo inter-religioso e só pode ser superado com a experiência fundamental da humildade". ${ }^{24}$

A experiência da humildade acontece quando se percebe que a verdade é plural e a abertura para o outro, onde se acolhe o outro, num sentimento de hospitalidade, assim como ele. Teixeira diz que "a maior resistência ao diálogo advém de pessoas ou grupos

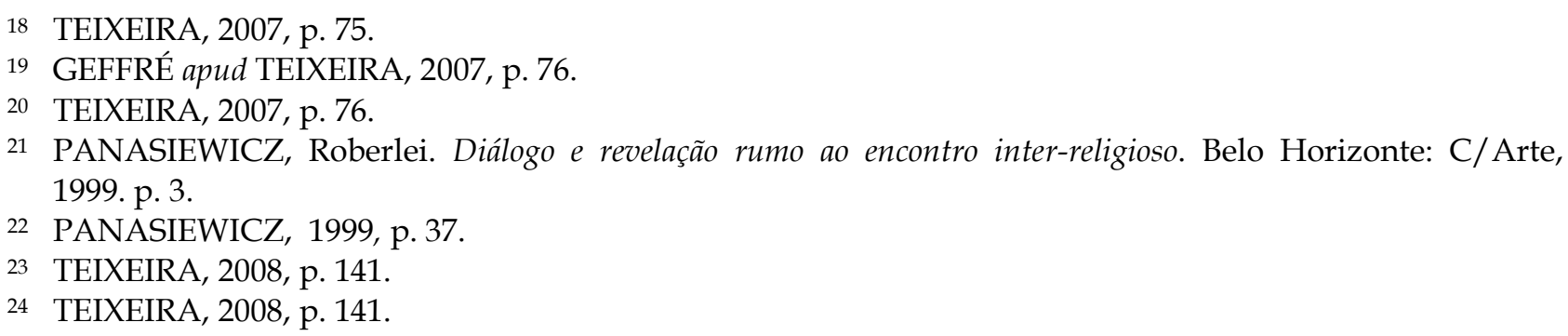


animados pela autossuficiência e arrogância identitária". ${ }^{25}$ Vencer a arrogância, tornar-se humilde e um eterno aprendiz são atitudes essenciais ao diálogo. Para Sanches, "dialogar é sair de si para conhecer o outro e estar disponível para ser solidário com a sua vida, e, abrir mão da intransigência e do fundamentalismo que impedem a convivência fraterna". ${ }^{26} \mathrm{O}$ ser humano é social e relacional. A comunicação faz parte da vida, não somos uma ilha isolada. Não pode haver religião sem "religare" ou religar. Isto implica na religação do próximo ao próximo, ou seja, estar aberto ao nosso semelhante, numa atitude de humildade.

As mudanças de atitudes, comportamentos, surgem através do viés da comunicação das experiências no encontro com o outro. $\mathrm{O}$ diálogo inter-religioso desenvolverá uma nova mentalidade de revelação não pensada ou interpretada nos parâmetros do cristianismo tradicional. Há uma promessa para todo ser humano dentro da cultura na qual se encontra. André Torres Queiruga aponta para uma nova forma de entender a revelação. "A revelação como maiêutica 'a arte da parteira' compreender-se a si mesmo a partir das demais religiões e compreender as demais religiões a partir da vivencia e da interpretação da religião à qual se percebe". ${ }^{27}$

Panasiewicz salienta que para Geffré é mais importante falar em metamorfose do sagrado, ou seja, o sagrado não desapareceu com a crítica da Modernidade, e foi a maneira de perceber que a igreja ainda detém a monopólio do sagrado. Enquanto monopólio, não pode existir diálogo, o casulo da tradição precisa ser rompido para a liberdade da linda borboleta da união, do respeito, do entendimento da paz e do amor universal. ${ }^{28}$

Portanto, o diálogo inter-religioso requer também respeito à alteridade do interlocutor e a abertura ao valor de sua convicção, sendo também uma forma de, além de conhecer o outro, conhecer-se a si mesmo, descobrindo-se também como um ser plural. A descoberta da pluralidade é uma marca do tempo que vivemos. Como afirma Teixeira: “o outro humano é um patrimônio de mistério que se revela a cada momento, deixando sempre adiante uma nova virtualidade a ser captada". ${ }^{29}$ Entretanto, não existe diálogo sem uma fidelidade a si mesmo e ao seu próprio engajamento de fé. Teixeira afirma: "não pode haver diálogo sem um ancoradouro referencial. É necessário estar domiciliado em alguma tradição para poder vivenciar em profundidade a abertura ao universo do outro" . ${ }^{30}$ Para haver diálogo, é necessário conhecer-se a si mesmo e à sua própria comunidade de fé. $\mathrm{O}$ diálogo só acontece a partir de pessoas que conhecem bem sobre o que elas estão dialogando.

\footnotetext{
TEIXEIRA, 2007, p. 76.

SANCHES, Wagner Lopes. O Vaticano II e o diálogo inter-religioso. São Paulo: Paulus, 2015. p. 14.

QUEIRUGA, Andrés Torres. Auto-compreensão cristã: diálogo das religiões. São Paulo: Paulinas 2007. p. 18.

28 PANASIEWICZ, Roberlei. Pluralismo religioso contemporâneo: dialogo inter-religioso na teologia de Claude Geffré . São Paulo: Paulinas; Belo Horizonte: PUC, 2007. p. 110.

29 TEIXEIRA, 2007, p. 76.

30 TEIXEIRA, 2007, p. 76.
} 
De acordo com o autor mencionado, "os interlocutores do diálogo devem estar também disponíveis e abertos ao mistério que os envolve e ultrapassa. A busca comum da verdade é um dos importantes traços da aventura dialogal" ${ }^{31} \mathrm{O}$ diálogo inter-religioso implica reconhecer que existem valores em todas as tradições religiosas e que nelas aprendemos a manifestação do sagrado, do mistério, daquilo que nos transcende, de Deus. Portanto, o diálogo inter-religioso não acontece no vazio, mas a partir da tradição religiosa de cada interlocutor, que se abre para ouvir da tradição religiosa do outro. Neste processo de abertura de um para o outro se realiza um processo de aprendizagem mútua e de admiração pelo outro. Teixeira enfatiza a abertura ao valor da alteridade, quando afirma:

O diálogo só pode acontecer quando se reconhece e respeita a alteridade do interlocutor, bem como o valor de sua convicção. [...] O outro é 'mysterium tremendum', que jamais pode ser completado ou reduzido em seu significado último. Essa realidade da diferença não implica a impossibilidade de abertura ou comunicação, pois o outro é igualmente 'mysterium fascinans', enquanto convida ao encontro e se disponibiliza ao aprendizado da diferença. 32

O diálogo inter-religioso além de ser um convite ao encontro com o outro é também um aprendizado da diferença. Neste sentido, Teixeira aponta um terceiro elemento fundamental no diálogo inter-religioso que é a fidelidade à própria tradição. Como já foi afirmado anteriormente por Teixeira, “o diálogo ganha riqueza e sustentação quando acompanhado pelo aprofundamento do próprio compromisso identitário". ${ }^{33}$ Assim, no diálogo não se nega a própria tradição, mas aprofunda-se no encontro com o outro. Um outro aspecto importante que necessita ser ressaltado é a busca comum da verdade. Teixeira salienta que:

No encontro com o outro abre-se a possibilidade de captar dimensões inusitadas desta verdade que é aletheia: permanente desvelamento. O outro é capaz de favorecer a seu interlocutor, no diálogo, a captação de certos aspectos ou dimensões do mistério divino que escapam à sua visada. ${ }^{34}$

Portanto, a verdade é plural e ela se encontra de forma diferente nas tradições religiosas. Além do mais, é necessário deixar claro que sempre só se capta uma parte da verdade. Ninguém consegue captar a verdade em sua totalidade. Teixeira entende que: “o

\footnotetext{
TEIXEIRA, 2007, p. 76.

TEIXEIRA, 2008, p. 143-144.

TEIXEIRA, 2008, p. 145.

TEIXEIRA, 2008, p. 146.
} 
que dificulta o diálogo é a incapacidade de compreender que a realidade última não pode estar limitada às imagens particulares das crenças". ${ }^{35}$

Não por último, o diálogo deve, segundo o autor citado significar também para seus interlocutores o desafio de assumir a responsabilidade global de afirmação do humano e do cuidado com toda a criação. ${ }^{36}$ "Cresce hoje a consciência de que o sofrimento dos seres humanos e a devastação do planeta devem constituir a base fundamental para o encontro e o diálogo entre as tradições religiosas". ${ }^{37}$ Despertar a compaixão humana pelos pobres e a criação em sua totalidade é parte integrante do diálogo inter-religioso. Teixeira aponta para estes pontos fundamentais do diálogo interreligioso. ${ }^{38}$

\section{Conclusão}

O reconhecimento da pluralidade religiosa é o primeiro passo para uma convivência cidadã e democrática no Brasil. As diferentes tradições religiosas tornam a cultura brasileira mais diversificada e rica. No entanto, como foi possível perceber, a intolerância religiosa se faz presente no cotidiano, manifestando-se, especialmente, contra as religiões de matriz africana. Portanto, urge o diálogo inter-religioso que aponta para o reconhecimento da diferença, a importância da alteridade e a necessidade de conhecer o outro. $\mathrm{O}$ diálogo entre diferentes edifica e fortalece a vivência da espiritualidade. Ribeiro assinala que "no diálogo, há uma mudança e a criação de um lugar fértil para a espiritualidade". ${ }^{39} \mathrm{O}$ diálogo inter-religioso é fundamental para a superação da intolerância religiosa.

A humanidade se completa no diálogo, na compreensão do outro e no respeito mútuo. A vida humana em todos os aspectos; tanto religioso, emocional ou psicológico, está em constante construção que acontece fora da clausura de si mesmo. Destaca-se no diálogo inter-religioso, primeiramente, uma atitude de humildade, seguida da alteridade, conduzindo para a abertura ao outro e, desta forma, um enriquecimento mútuo para todos e todas envolvidos e envolvidas no diálogo.

O diálogo inter-religioso para se realizar necessita que cada um conheça profundamente a sua tradição de fé, para poder se abrir e vivenciar em profundidade a abertura ao universo de fé do outro. A busca da verdade, que é plural, é uma das aventuras do encontro dialogal. Além do mais, o diálogo inter-religioso leva ao compromisso social, como as grandes questões que envolvem a humanidade, por exemplo, os processos migratórios, a fome, as guerras e o cuidado com toda a criação. A

35 TEIXEIRA, 2008, p. 147.

36 TEIXEIRA, 2007, p. 76.

37 TEIXEIRA, 2007, p. 76.

38 TEIXEIRA, 2007, p. 77.

39 RIBEIRO, 2014, p. 72. 
partir do encontro com o outro, numa atitude dialogal humilde e comprometida com a vida em sua integralidade, crescerá também o compromisso com a superação do sofrimento que envolve seres humanos, especialmente os mais pobres e com o planeta Terra, que é habitado por todos, independentemente, da tradição religiosa.

\section{Referências}

BOURDIEU, Pierre. A economia das trocas simbólicas. São Paulo: Perspectivas, 2007.

GABATZ, Celso. Religiosidade Brasileira Contemporânea: Pluralismo, secularização e múltiplas pertenças. Anais do Congresso Internacional da Faculdades EST. v. 2. São Leopoldo: EST, 2014. Disponível em:

<http://anais.est.edu.br/index.php/congresso/article/viewFile/256/218>. Vários acessos.

INSTITUTO BRASILEIRO DE GEOGRAFIA E ESTATÍSTICA - IBGE. Censo Demográfico 2010: características gerais da população, religião e pessoas com deficiência. Rio de Janeiro: IBGE: Censo demográfico, 2010.

MACHADO, Gerson. Violência contra os Axés. Revista Semestral de Teologia e Ciências das Religiōes, v. 9, n. 14, p. 257-273, 2015. Disponível em:

<http://revista.faculdadeunida.com.br/index.php/reflexus/article/view/296/295>. Acesso em: 20 jan. 2016.

MARIANO, Ricardo. Mudanças no campo religioso brasileiro no Censo 2010. Debates do NER, Porto Alegre, ano 14, n. 24, p. 119, jul./dez. 2013. Disponível em:

<http://www.seer.ufrgs.br/debatesdoner/article/download/43696/27488>. Acesso em: 20 dez. 2016.

PANASIEWICZ, Roberlei. Diálogo e revelação rumo ao encontro inter-religioso. Belo Horizonte: C/Arte, 1999.

. Pluralismo religioso contemporâneo: dialogo inter-religioso na teologia de Claude

Geffré . São Paulo: Paulinas; Belo Horizonte: PUC, 2007.

QUEIRUGA, Andrés Torres. Auto-compreensão cristã: diálogo das religiões. São Paulo: Paulinas 2007.

RIBEIRO, Claudio de Oliveira. Pluralismo e libertação. São Paulo: Paulinas, 2014.

SANCHES, Wagner Lopes. O Vaticano II e o diálogo inter-religioso. São Paulo: Paulus, 2015.

TEIXEIRA, Faustino. O diálogo inter-religioso. In: TEIXEIRA, Faustino; DIAS, Zwinglio Mota. Ecumenismo e diálogo inter-religioso: a arte do possível. Aparecida: Santuário, 2008.

. Teologia e diálogo inter-religioso. ALMEIDA, Edson Fernando de; LONGUINI NETO, Luiz (Orgs.), Teologia para quê? Rio de Janeiro: Mauad, 2007. 